\title{
THE EFFECT OF TIDE LEVEL ON THE TSUNAMI RESPONSE OF COASTAL HARBORS
}

\author{
Jiin-Jen Lee ${ }^{1}$, Ziyi Huang ${ }^{1}$, Zhiqing Kou ${ }^{1}$, and Xiuying Xing ${ }^{2}$
}

\begin{abstract}
The tsunamis generated by the February 27, 2010 Chilean earthquake and the great Japan Tohoku earthquake on March 11, 2011 arrived at several Pacific Coast harbors when the tide levels were at low tides and persisted for several tidal cycles. Despite the significant difference in the recorded wave amplitude observed at Crescent City harbor between these two events, the energy spectrum as a function of frequency has been found to contain several spikes corresponding to the frequency range of $3 \times 10^{-4} \sim 10 \times 10^{-4} \mathrm{~Hz}$. This pattern in spectral density is different from several prior tsunamis observed and analyzed for Crescent City Harbor as presented by Lee, Xing and Magoon (2008). In the present study we present the reasons behind the differences in the response behavior associated with these two events. We prove that they are due to the effect of tide levels. We also show that in order to correctly decipher the resonant response characteristics to incident wave the response curves should be expressed as a function of the dimensionless wave number. The tsunami waves recorded at tide gauge station in San Diego Harbor (Southern California) are also analyzed and discussed.
\end{abstract}

Keywords: harbor resonance; Chilean earthquake tsunami; Tohoku tsunami; dimensionless wave number; fundamental resonant mode; Crescent City Harbor; San Diego Harbor

\section{INTRODUCTION}

On February 26, 2010, at 22:34 PST, a magnitude 8.8 earthquake occurred in south-central coastal region of Chile approximately $300 \mathrm{~km}$ north of the site of the massive 1960 Chile earthquake $\left(\mathrm{M}_{\mathrm{w}}=9.5\right)$. A large tsunami was generated causing severe damage to coastal towns and harbor facilities along Chilean coastal region. The generated tsunami waves propagated throughout Pacific Ocean. They arrived at California coast about $12 \sim 13$ hours later. The wave trains had been recorded at several tidal gauges located along the California coast.

Crescent City Harbor located in Northern California is well known for its tsunami vulnerability due to its location and topography. Consequently, many authors have described the harbor as a "sitting duck" for tsunami waves originated from Pacific Ocean (Magoon 1965; Powers 2005). The tidal gauge record from 02/27/2010 14:00 PST to 03/01/2010 14:00 PST at Crescent City Harbor for Chilean earthquake tsunami is shown in Figure 1. The wave spectral density obtained from the recorded waves after separating the tide is shown in Figure 2.

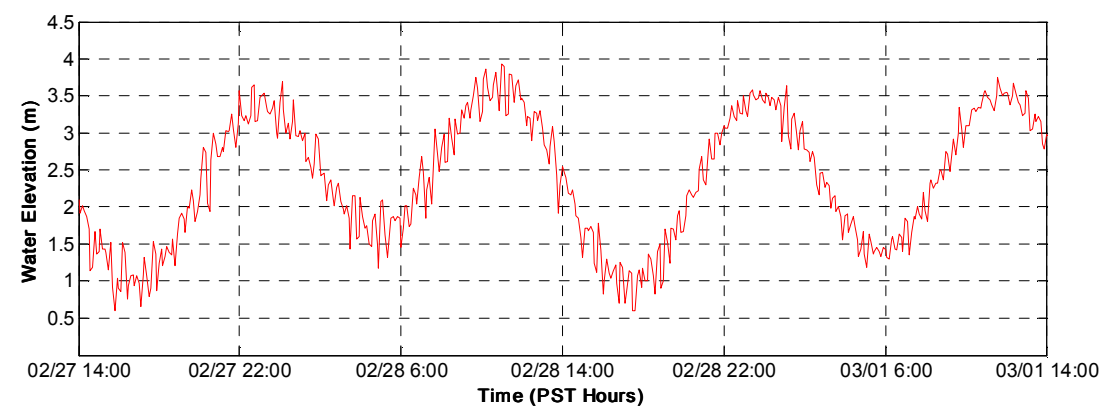

Figure 1. Marigram at the location of Crescent City Harbor tidal gauge for February 26, 2010 Chilean earthquake-generated tsunami event (recorded by U.S. National Ocean Service Station 9419750).

On March 11, 2011 massive tsunami waves were generated by great Japan Tohoku earthquake. The water surface oscillations recorded at the same tidal gauge station in Crescent City Harbor are shown in Figure 3. The wave spectral density obtained from the recorded wave profiles at the tidal gage station is shown in Figure 4.

From Figure 2 it is seen that the spectral density contains numerous peaks within the frequency range between $3 \times 10^{-4} \sim 10 \times 10^{-4} \mathrm{~Hz}$. In spite of larger wave amplitude, similar spectral pattern can also be seen in Figure 4 for Japan event. In an earlier study by Lee, Xing and Magoon (2008) several tsunamis (including local and distant tsunami recorded) at Crescent City Harbor were analyzed. The spectral density curves for those four prior tsunamis are shown in Figure 5.

\footnotetext{
${ }^{1}$ Department of Civil and Environmental Engineering, University of Southern California, 3620 South Vermont Avenue, Los Angeles, CA, 90089, USA

${ }^{2}$ Moffatt \& Nichol Engineers, 3780 Kilroy Airport Way, Long Beach, CA, 90808, USA 


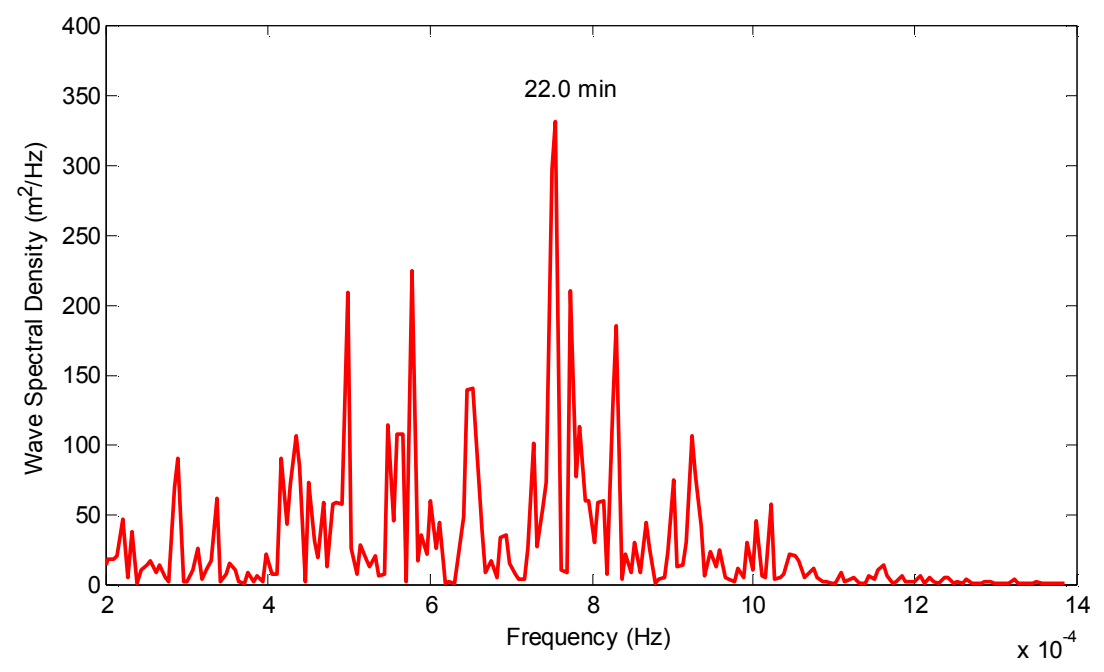

Figure 2. Wave spectral density for the time series of wave oscillations at Crescent City Harbor tidal gauge location in the Chilean tsunami event.

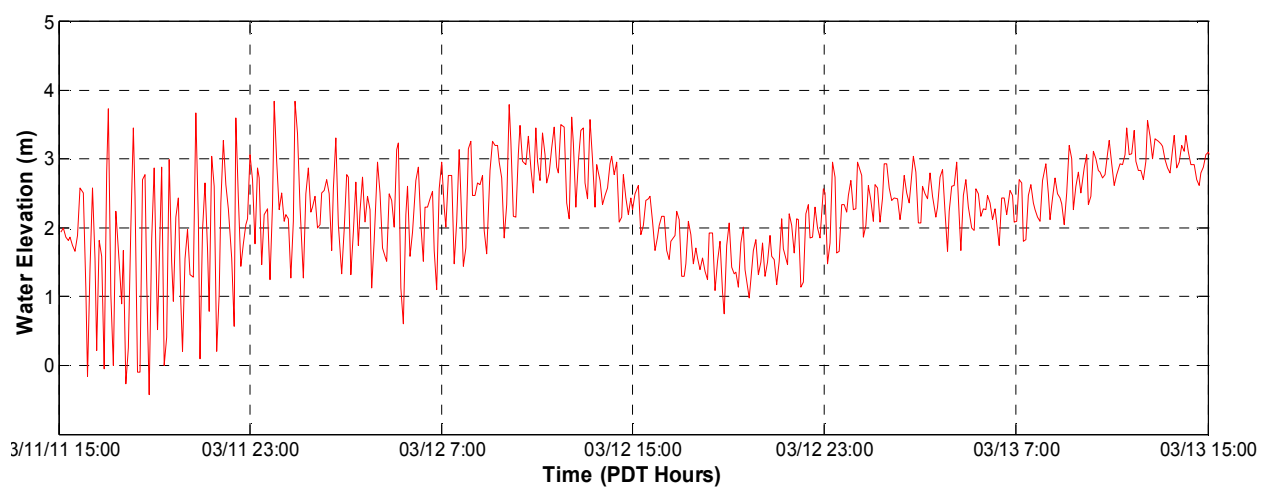

Figure 3. Marigram at the location of Crescent City Harbor tidal gauge for March 11, 2011 Japan earthquake-generated tsunami event (recorded by U.S. National Ocean Service Station 9419750).

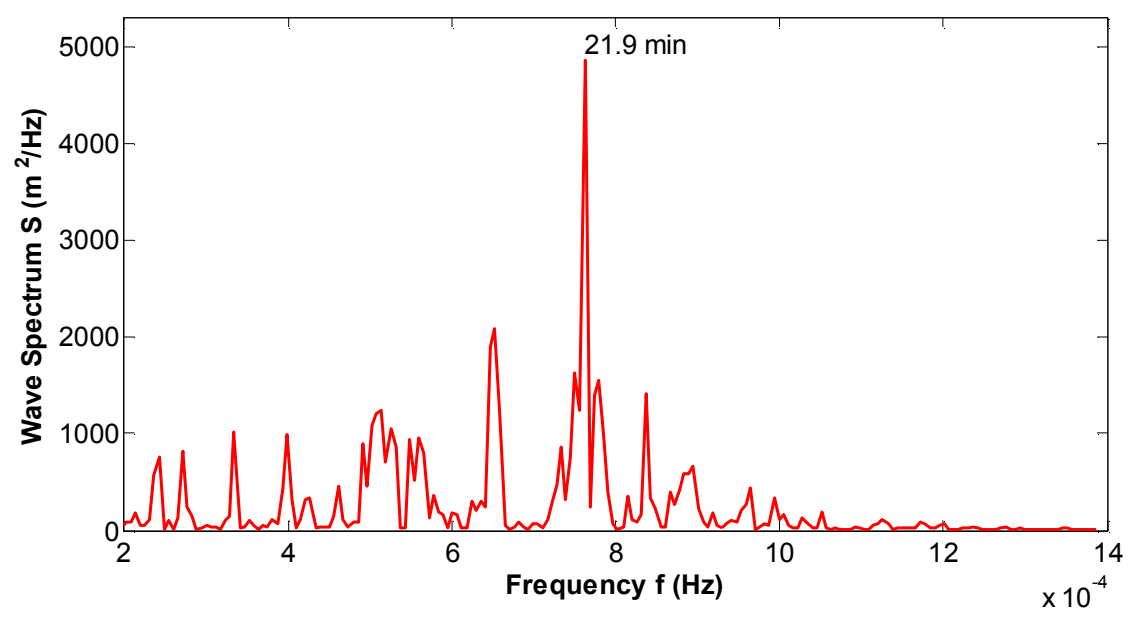

Figure 4. Wave spectral density for the time series of wave oscillations at Crescent City Harbor tidal gauge location in the Japan tsunami event. 

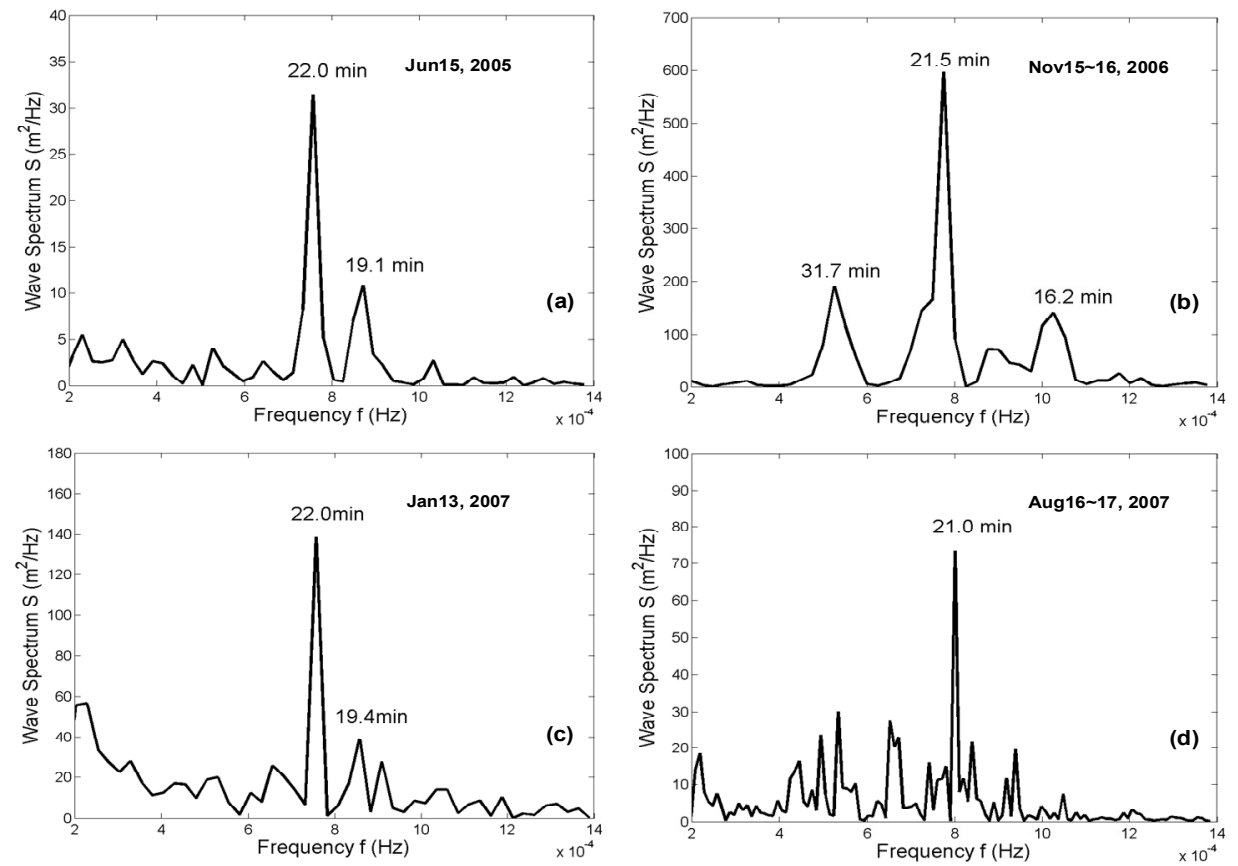

Figure 5. Wave spectral density of the recorded waves at Crescent City Harbor tidal gauge location on (a) Jun 15, 2005; (b) Nov 15 16, 2006; (c) Jan 13, 2007; (d) Aug 16 17, 2007.

A casual comparison of the energy spectral density of Chilean and Japan tsunami with Figure 5 would lead one to believe that the response to this Chilean tsunami wave at Crescent City Harbor is very different from the many prior tsunamis as shown in Figure 5. To discover the mystery of this discrepancy, the numerical model used in Lee, Xing and Magoon (2008) is reexamined closely.

\section{NUMERICAL MODEL AND SIMULATION RESULTS}

The numerical model used is a hybrid finite element model. For a more detail presentation of the numerical model used in this study see Lee and Xing (2010). The governing equation is the Mild Slope Equation first derived by Berkhoff (1972):

$$
\nabla \cdot\left(C C_{g} \nabla \phi\right)+\frac{C_{g} \omega^{2}}{C} \phi=0
$$

in which $\phi=\phi(x, y)$ is the velocity potential, $C=\omega / k$ is the wave celerity, $C_{g}=C / 2(1+G)=$ $C / 2(1+2 k h / \sinh 2 k h)$ is the group velocity, $k$ and $\omega$ are the wave number and the wave frequency, and $h$ is the water depth (which is a function of $x$ and $y$ ).

The numerical model incorporates the effects of variable water depth, wave refraction, wave diffraction, wave reflection from partially or fully reflecting boundaries, entrance energy dissipation, as well as wave transmission through porous breakwaters.

Figure 6(left) shows the model region for the computer model (only the major grid blocks are shown). The numerical model contains 9,709 finite elements and 39,688 nodes with eight incident wave directions (indicated as direction \#1 to \#8). Crescent City Harbor is shown in Figure 6(right) with five locations of interest denoted as A, B, C, D, and E with the tidal gauge location noted.

Figure 7 shows the computer simulation response curves obtained from the model with the two distinct resonant periods at the tide gauge station of Crescent City Harbor under different scenarios of assumed wave directions. The ordinate is the amplification factor defined as the wave height at the tide gauge station divided by the incident wave height. The abscissa is the dimensionless wave number $k l$ (where $k$ is the wave number, $2 \pi$ divided by the wave length $l$, and $l$ is the characteristic length of the harbor which is the length from the outer harbor entrance to the facing coastal line about 4.363 feet in the present model). It clearly shows that $22.0 \mathrm{~min}$ and $10.3 \mathrm{~min}$ resonant periods (based on the average water depth) existed at the tidal gauge station. 

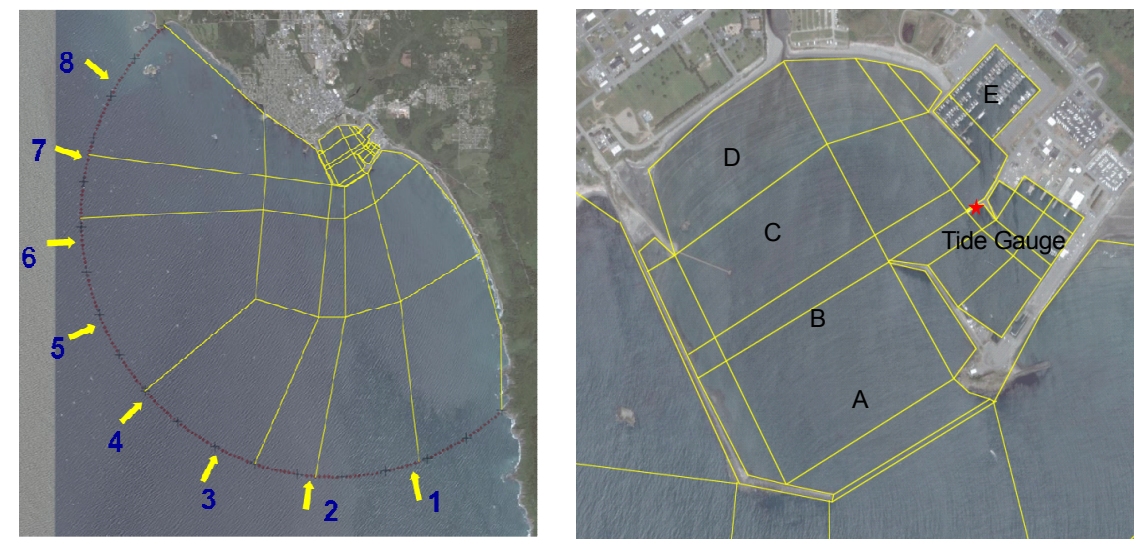

Figure 6. Simulation domain for Crescent City Harbor (left) and locations of special interest as A, B, C, D, E and tidal gauge (right).

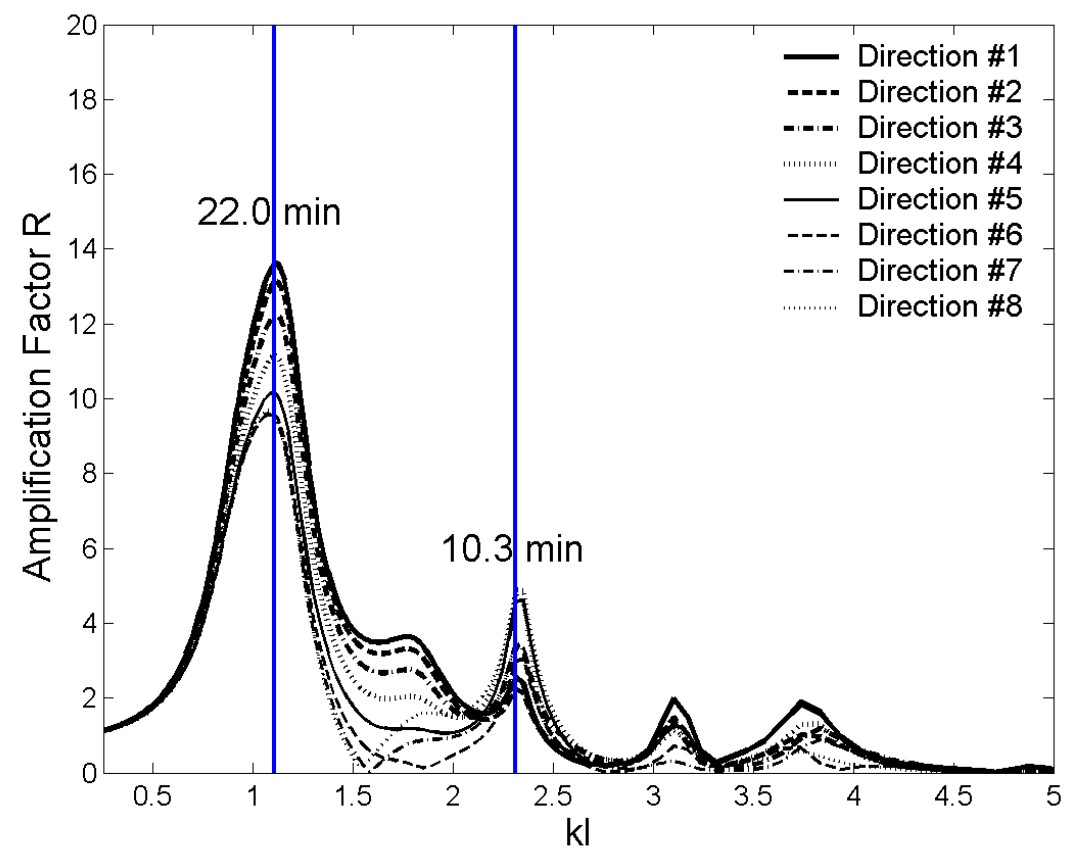

Figure 7. Simulated response curves at tidal gauge location for different incoming wave directions.

The response curves at locations A-E and tide gauge station with incident wave coming from direction 2 (oriented toward north) are shown in Figure 8. It is clear that the waves are amplified as the inner harbor region is approached for both the $22.0 \mathrm{~min}$ and $10.3 \mathrm{~min}$ resonant wave periods. Thus it appears that the more inner the location is, the larger the wave amplitude in accordance with the earlier general studies on harbor resonances (Lee 1971; Lee and Raichlen 1972; Zelt and Raichlen 1990). This explained the significant damage occurred in the small inner harbor (such as on November 15, 2006 Kuril Island earthquake) during which strong currents were invoked by the large oscillations. These large oscillations pushed boats against the berth facilities and colliding with other neighboring boats.

It is interesting to note that (as shown in Figure 6) at location $\mathrm{E}$ an amplification factor of 15 can be expected for the resonant wave period of $22.0 \mathrm{~min}$. Thus, at this resonant wave period, a large volume of water must enter the harbor through harbor entrance causing significant wave induced currents in the harbor basin thereby causing many damages to harbor facilities. 


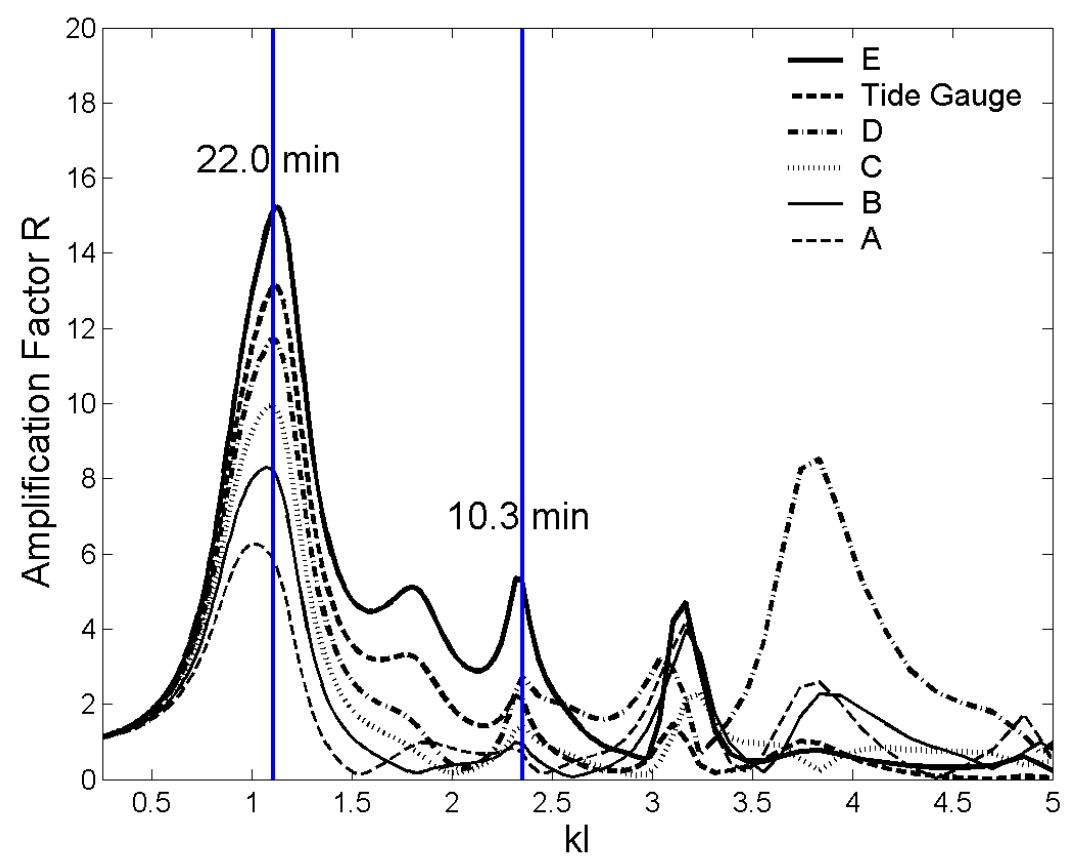

Figure 8. Response curves at locations noted by A-E and tidal gauge station with incident wave coming from direction 2.

The tsunami-genic events originated from the Pacific Rim locations from which the tsunami energy spectra shown in Figure 5 are indicated in Figure 9. These events include the near-field earthquake generated at offshore location in Northern California (June 15, 2005, magnitude of 7) and three far-field earthquakes. Two generated in Kuril Islands, Japan (November 15, 2006 and January 13, 2007, with magnitude of 8.3 and 8.1 respectively) and one generated in offshore of Peru (August 15, 2007, magnitude of 7.9). The record for the event on April 1, 2007 at Salomon Islands was unavailable. The Chilean earthquake which occurred on February 26, 2010 is also indicted.

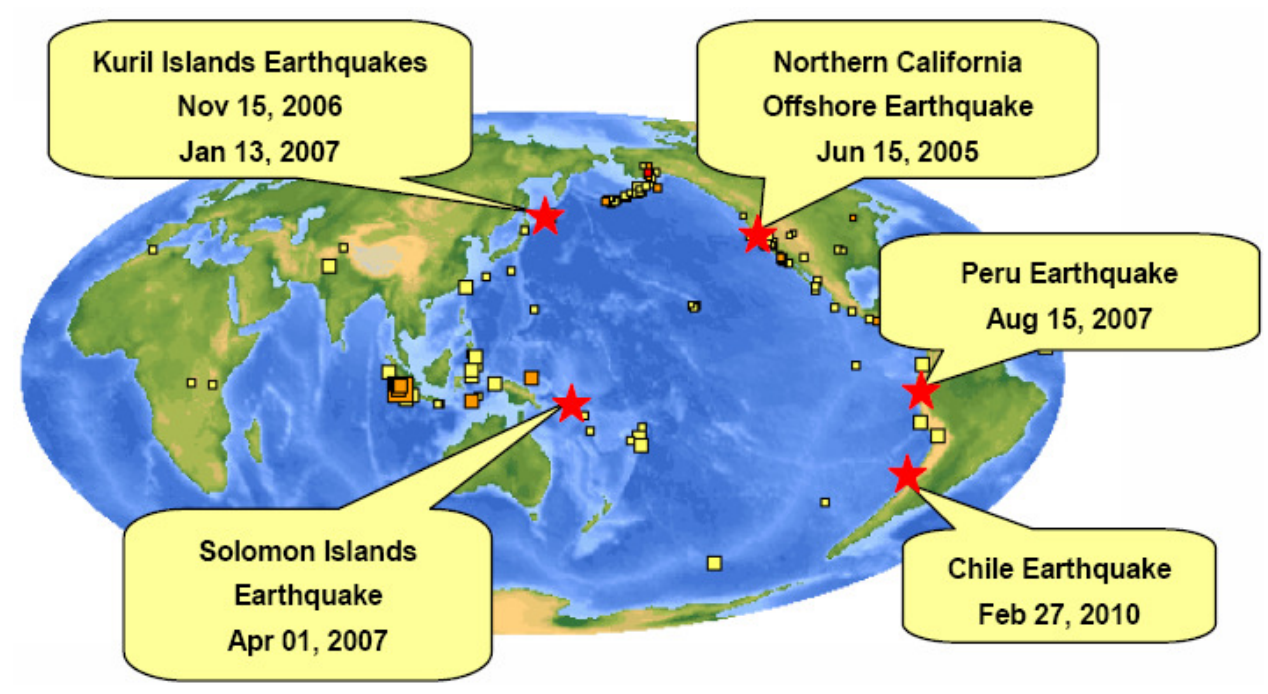

Figure 9. Epicenters and event times of recent earthquakes superimposed on USGS earthquake map.

The spectral curves of the wave records obtained at the tidal gauge station in Crescent City Harbor are shown earlier in Figure 5. It can be seen that the dominant waves in those events, which have the highest energy density, are all from 21 to 22 minutes as predicted in Figure 8. 
The approximate incoming wave directions in the four events are roughly from southwest for the Northern California earthquake, from west for the two Kuril Islands earthquakes, and from south for the Peru earthquake. The response curves obtained from the model for these incoming wave directions superimposed with the observed resonant waves corresponding to those events are plotted in Figure 10. The results indicate that the actual resonant periods are very close to those computed, especially for the fundamental mode at $22 \mathrm{~min}$.
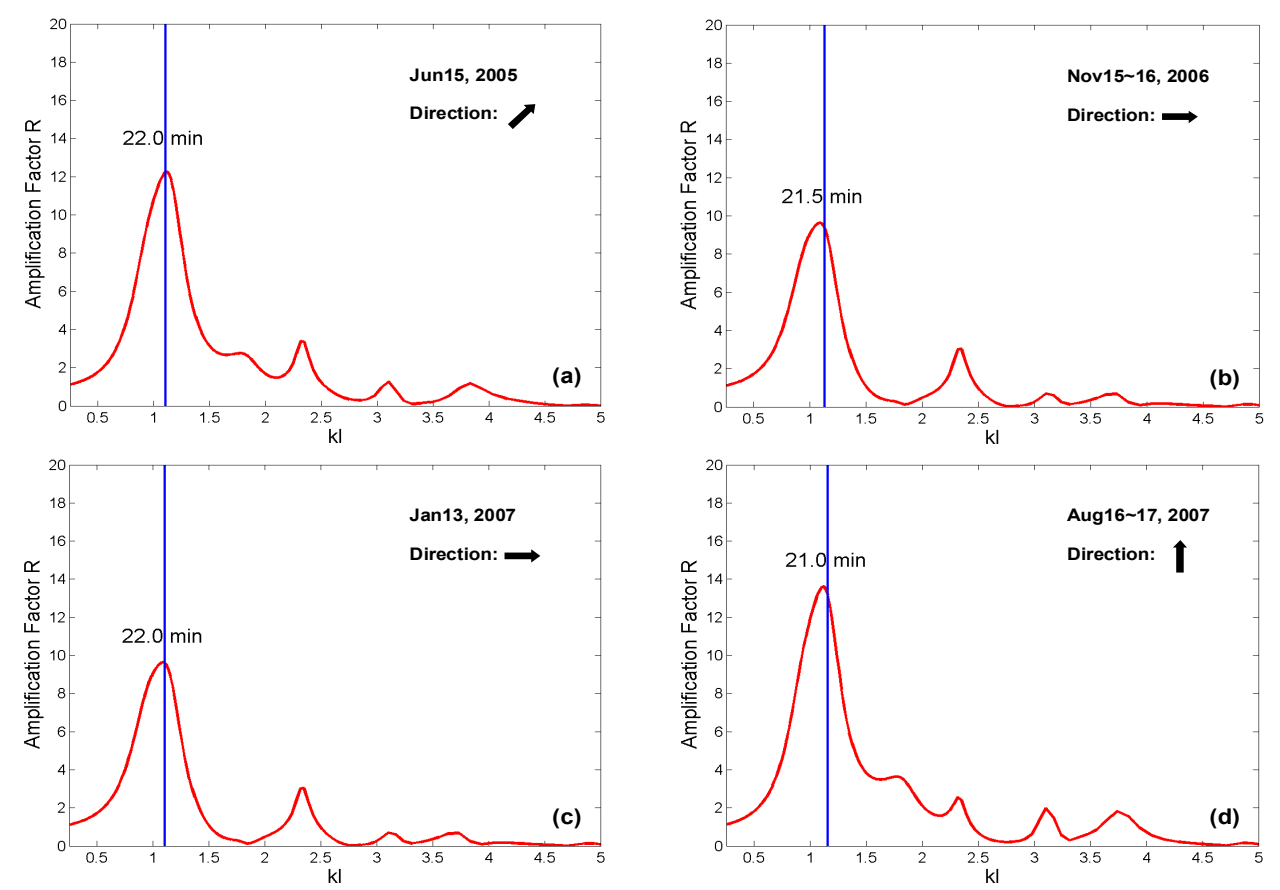

Figure 10. Response curves with observed dominant waves superimposed at Crescent City Harbor for events on Jun 15, 2005(a), Nov15, 2006(b), Jan 13, 2007(c), Aug 15, 2007(d).

\section{ENERGY SPECTRUM FOR CHILEAN EARTHQUAKE TSUNAMI}

For Chilean earthquake generated tsunami, the water level recorded by the tidal gauge at Crescent City Harbor covered the water depth from 0.6 to 3.9 meters. For clarity of discussion, the marigram in the time period of 02/27/2010 14:00 03/01/2010 14:00 PST and is repeated in Figure 11. Obviously, the water depth at low tide was only about $20 \%$ of the water depth at high tide level. After separating the tide, the time series of water surface is shown in Figure 12. The analyzed energy spectral density is presented in Figure 13.

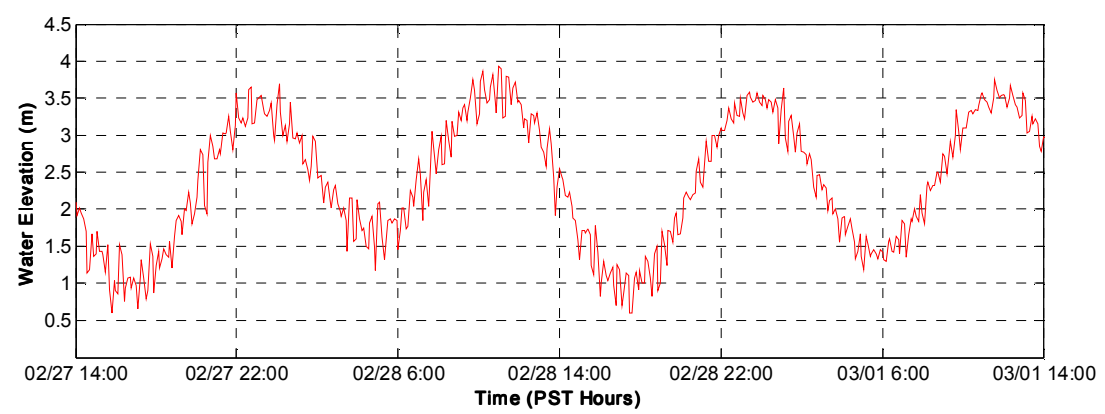

Figure 11. Marigram at the location of Crescent City Harbor tidal gauge for February 26, 2010 Chilean earthquake-generated tsunami event (recorded by U.S. National Ocean Service Station 9419750).

A direct comparison of Figure 13 with the spectral curves shown in Figure 5 would lead one to believe that the energy spectrum contained in the time series of $02 / 27 / 2010 \sim 03 / 01 / 2010$ is quite 
different from those presented in Figure 5 for other tsunami events. The answer to this observation lies in the fact that wave periods associated with the peak energy spectrum are significantly affected by the water depth.

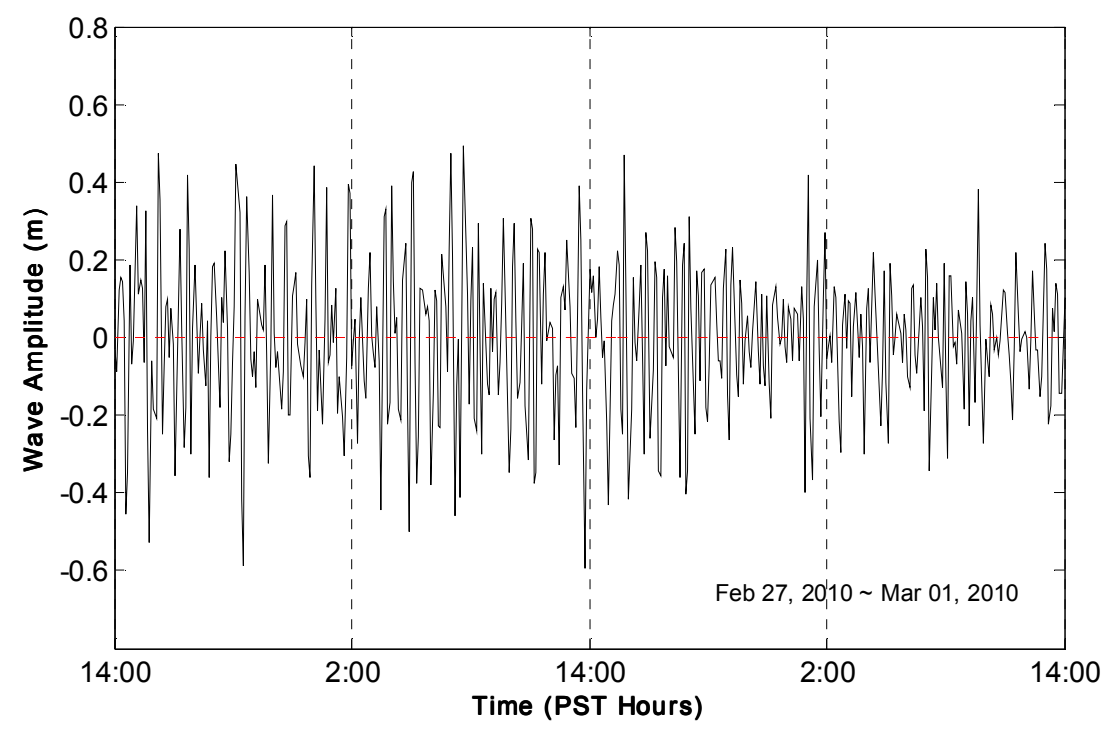

Figure 12. Tidal gauge record after eliminating the tide effect in Crescent City Harbor for Chilean earthquake event.

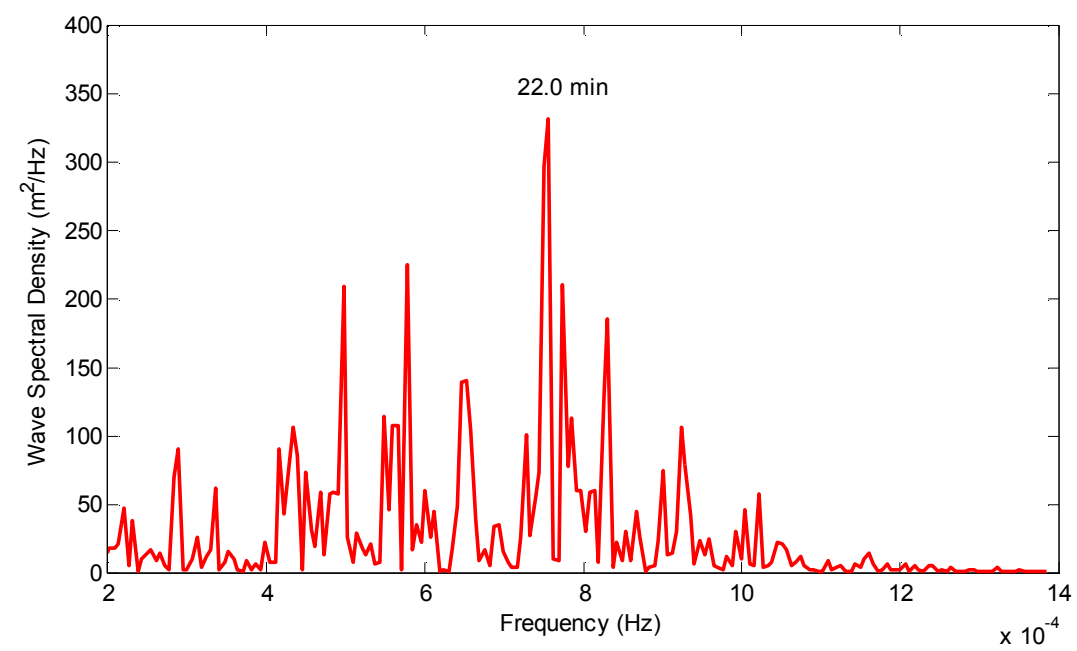

Figure 13. Wave spectral density for the time series of wave oscillations at Crescent City Harbor tidal gauge location during the Chilean tsunami event.

The relationship between the wave frequency and water depth associated with the resonant mode of $k l=1.10$ can be obtained from the dispersion relationship: $\sigma^{2}=g k \tanh k h$ (where $\sigma$ is the circular wave frequency, $k$ is the wave number, and $h$ is the water depth). Figure 14 shows the relationship of water depth vs. wave frequency and wave period for $k l=1.10$. For example, at water depth of 0.6 meter the first resonant mode $k l=1.10$ corresponds to the wave frequency at about $3.0 \times 10^{-4} \mathrm{~Hz}$ (or wave period of 56 minutes). Therefore, the various peaks in the energy spectrum shown in Figure 13 are resonant frequencies (also wave periods) associated with the same fundamental resonant mode at $k l=1.10$ as predicted in Figure 7 and Figure 8. They manifested in the spectral curve shown by Figure 13 in the many spikes in the frequency range $3 \times 10^{-4} \sim 10 \times 10^{-4} \mathrm{~Hz}$, but they are all associated with the fundamental resonant mode at $k l=1.10$ for different water depth. This 
observation further reinforced the importance and usefulness for computing the response curves such as those presented in Figure 7 and Figure 8 for correctly identifying the resonant modes. The importance of obtaining the response curve as a function of the dimensionless wave number $\mathrm{kl}$ has been previously shown in Lee (1971) and Raichlen \& Lee (1992).

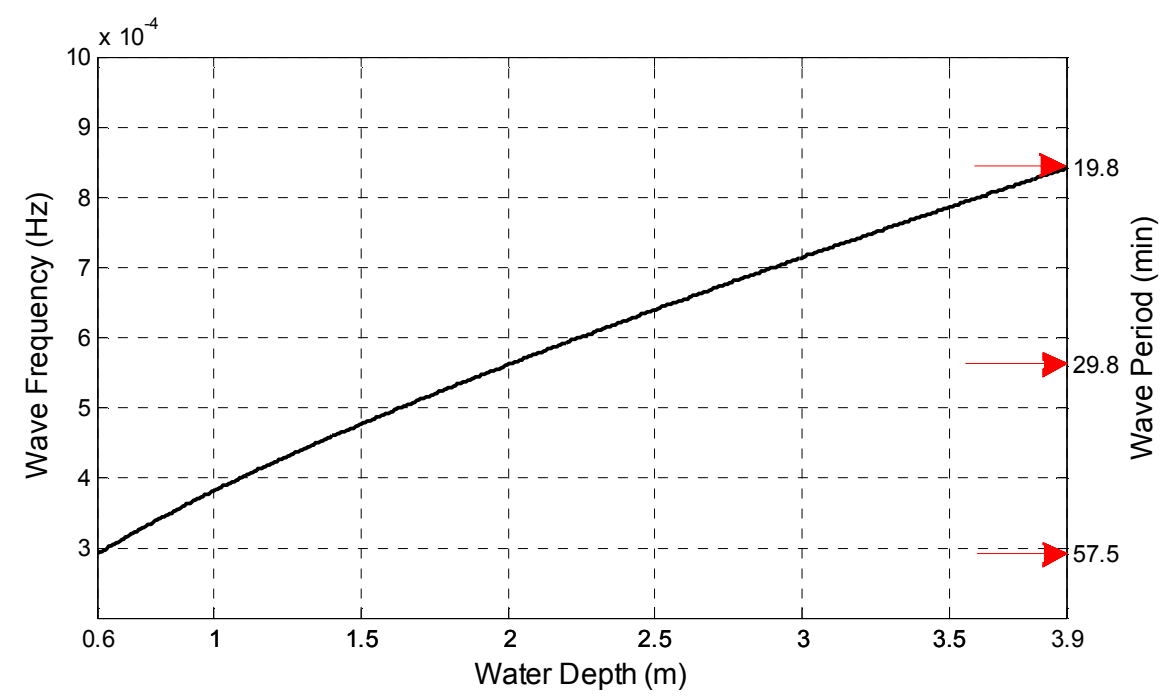

Figure 14. Relationship of water depth vs. wave frequency and wave period for $k l=1.10$.

To further confirm this major observation we have performed the spectral analyses of the tidal gauge record shown in Figure 11 by dividing the record into four different segments of water depth: 1.5 $\sim 2.0$ meters, $2.0 \sim 2.5$ meters, $2.5 \sim 3.0$ meters, $3.0 \sim 3.5$ meters. The spectral density curves are shown in Figure 15 for the corresponding water depth ranges. It is seen that the peak spectrum occurred at lower frequencies (longer wave periods) as the water depth was reduced as can be expected.
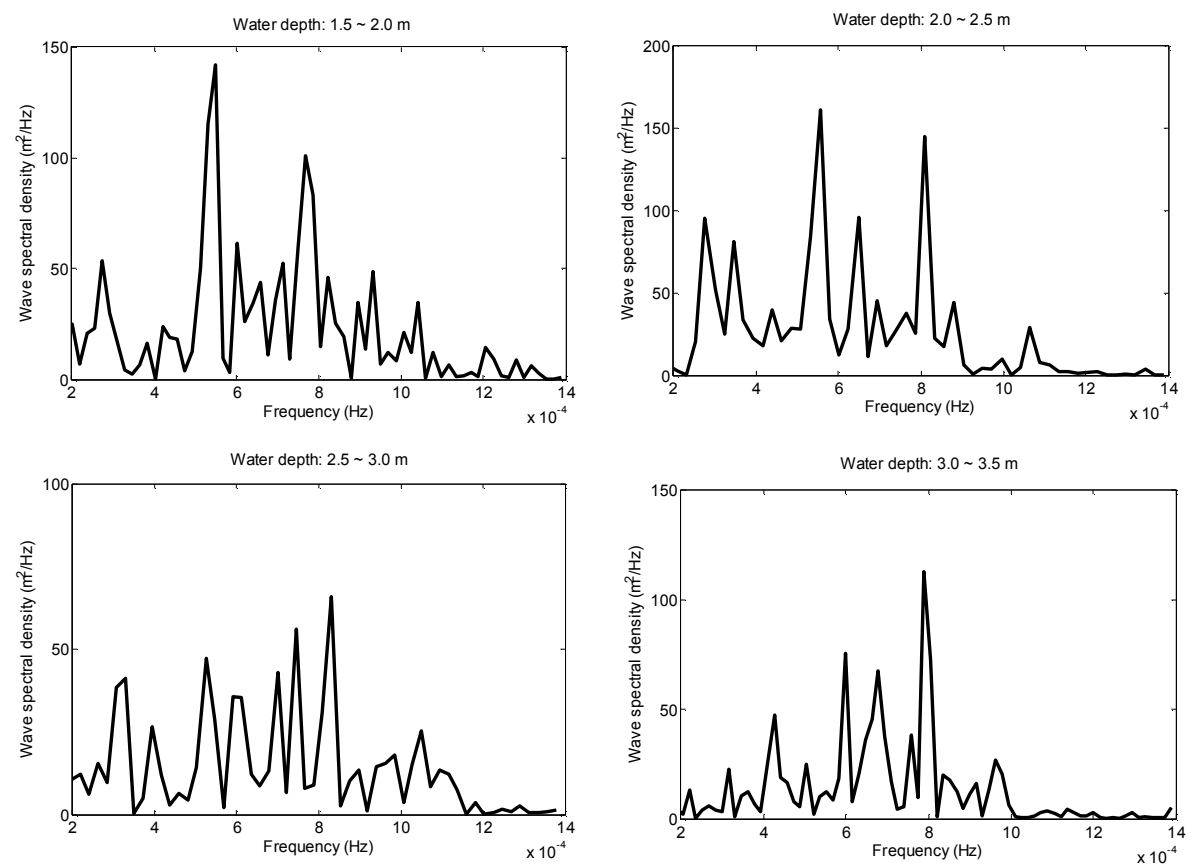

Figure 15. Wave spectral density for the times series of wave oscillations in different water depth ranges for Chilean earthquake event 


\section{ENERGY SPECTRUM FOR NORMAL DAYS}

The results presented in last section shows that the multiple peaks in the energy spectrum are the resulting wave periods due to changing water depth associated with the fundamental resonant mode at $k l=1.10$ as predicted in the numerical model. It is interesting to examine the record associated with the conditions in normal days at Crescent City Harbor. The time series of the water level recorded at Crescent City Harbor tidal gauge station on a normal day, July 21, 2008, are analyzed. They are presented in Figure 16 and Figure 17. It is seen from Figure 17 that multiple peaks in spectral curve also existed in the frequency range of $3 \times 10^{-4} \sim 10 \times 10^{-4} \mathrm{~Hz}$ (however the energy level is very low in comparison with tsunami waves). This pattern is similar to the spectral curve shown in Figure 13 because the tide level in Crescent City Harbor covers a wide range of water depth from 0.6 to 4 meters. As a result, multiple resonant periods are also manifested in the spectral curve associated with the fundamental resonant model at $k l=1.10$.

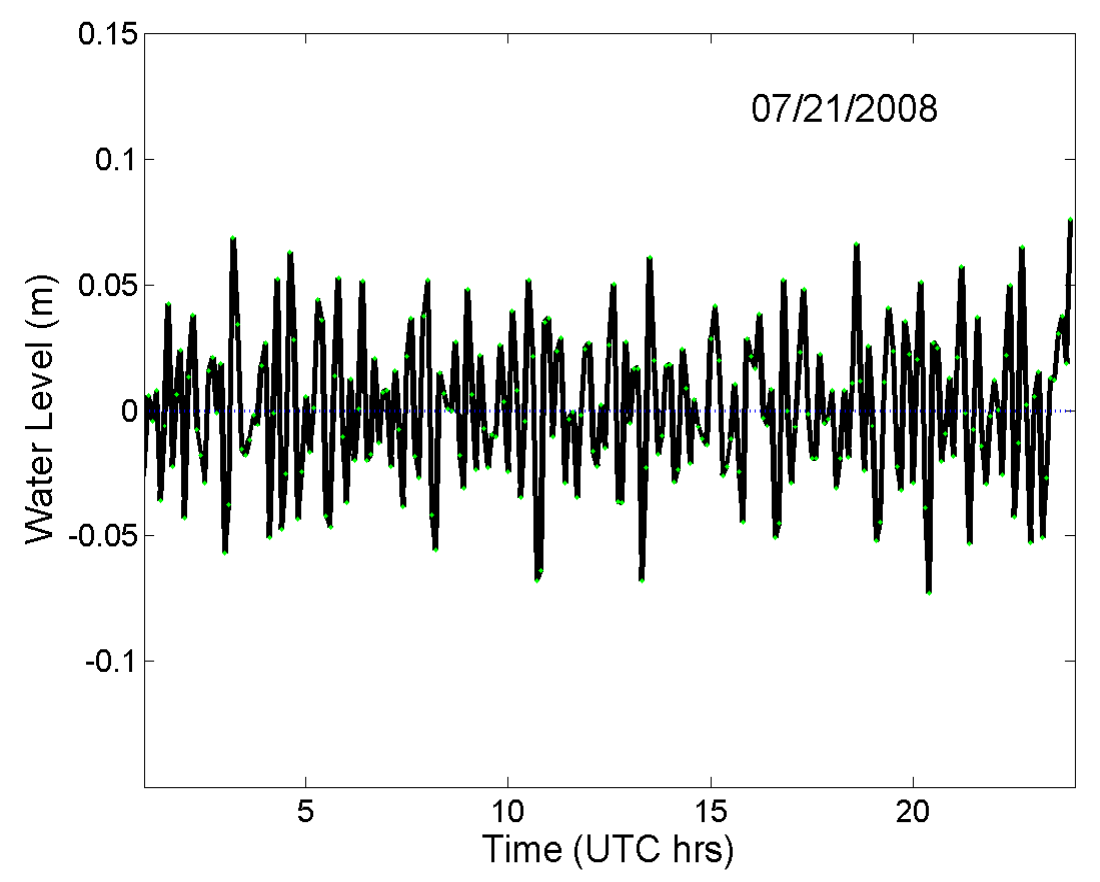

Figure 16. Time series of water level without tide effect at Crescent City Harbor tidal gauge station on July 21, 2008.

This evidence of background water level recorded at Crescent City Harbor further reinforced the existence of resonant modes of oscillations in the harbor even visible on normal days. Therefore, when large external incident wave trains hit the harbor (such as the earthquake generated tsunami waves) significant amplification to them can be expected based on the computed response characteristics of the harbor.

\section{SAN DIEGO HARBOR}

San Diego Harbor is located in the southwestern corner of California. The harbor is $25 \mathrm{~km}$ in length and 1-3 km in width shaping like a crescent as shown in Figure 18(a). It is one of the best natural bays with kelp forest on the western side, and large mud-flat in the south of the harbor as the habitats for many endangered and threaten species of plants and animals. The commercial port in the harbor ranked as the $30^{\text {th }}$ containership port in US. It has two container ship facility and a cruise ship terminal, and three other facilities owned by the US Navy. When the Chilean tsunamis (2010) arrived at San Diego Harbor, dramatic drawdown and minor flooding were observed in the harbor and the docks and boats were damaged at Shelter Island (Wilson et al. 2010). The 2011 Japan Tohoku tsunami broke a barge, crushed a portion of a dock, and damaged multiple boats moored in the harbor (Gehlken et al. 2011).

The simulation domain is shown in Figure 18(b) with incoming wave direction from south 
illustrated. The radius of the semi-circle enclosed the simulation region is about $1914 \mathrm{~m}$. The simulation domain includes 13,480 finite elements and 55,207 nodes. The bathymetry grid of the harbor is constructed based on the NOAA nautical chart 18773 with a scale of 1:12,000.

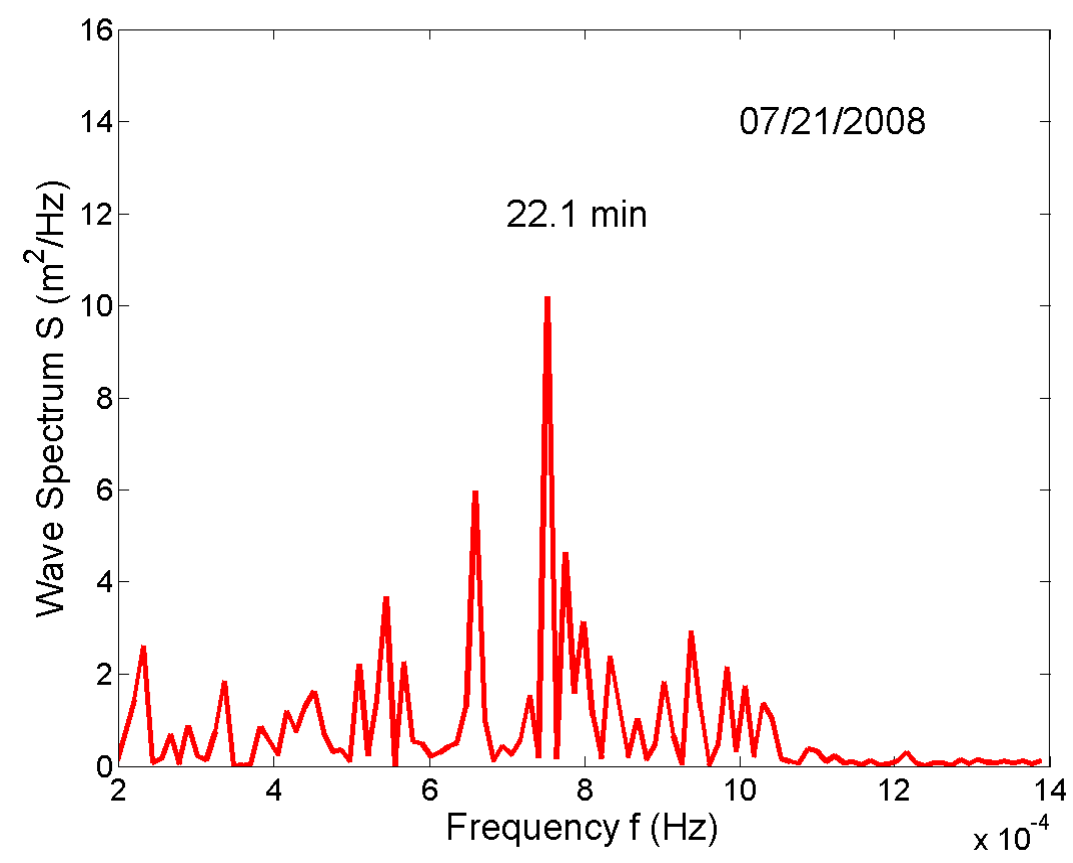

Figure 17. Wave spectrum of the water level time series at Crescent City Harbor tidal gauge station on July 21, 2008.
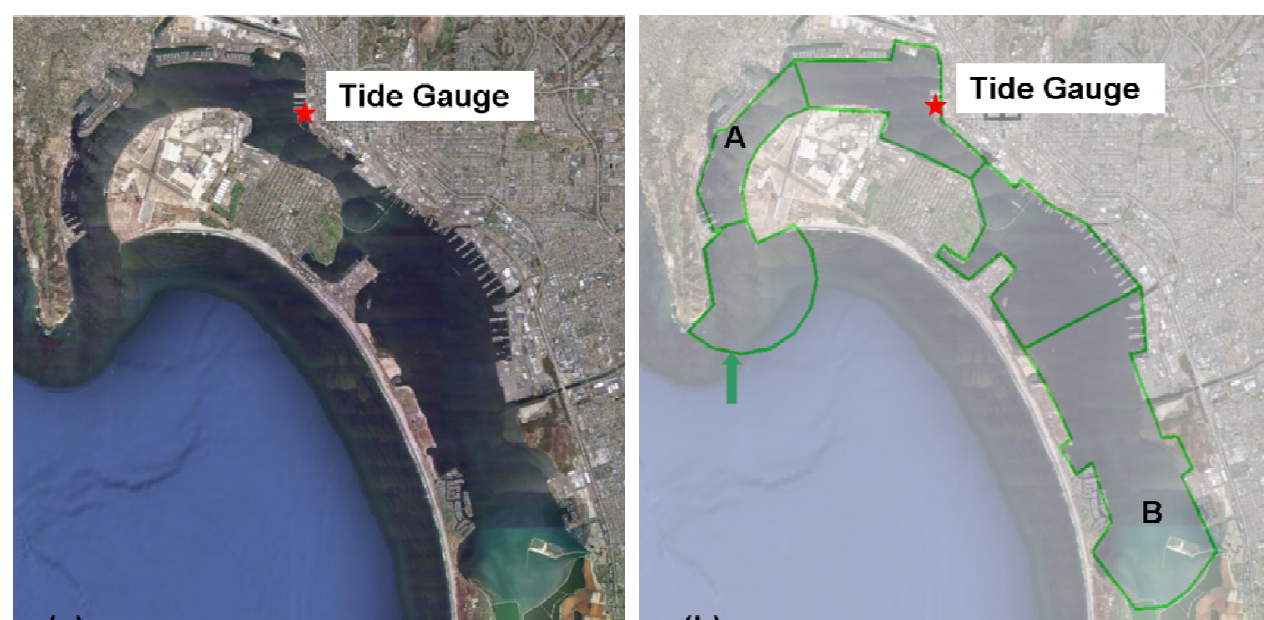

Figure 18. (a) Air photo of San Diego Harbor (b) Simulation domain.

The computed response curves at the tide gauge location as well as at location A and B with wave direction from south are presented in Figure 19. As shown in Figure 19 San Diego harbor has many resonant periods within the period ranges presented, mainly due to the long and narrow shape of the harbor itself. They are: $275 \mathrm{~min}, 86 \mathrm{~min}, 58 \mathrm{~min}, 40 \mathrm{~min}, 37 \mathrm{~min}$ and $34 \mathrm{~min}$. The first mode is at 275 min (pumping mode) in which the waves inside the whole harbor have the same phase, with larger wave amplitude at the most inner locations. From Figure 19 the amplification factor at location B is much larger than that at location A and the tidal gauge station for the first two modes of oscillation. 


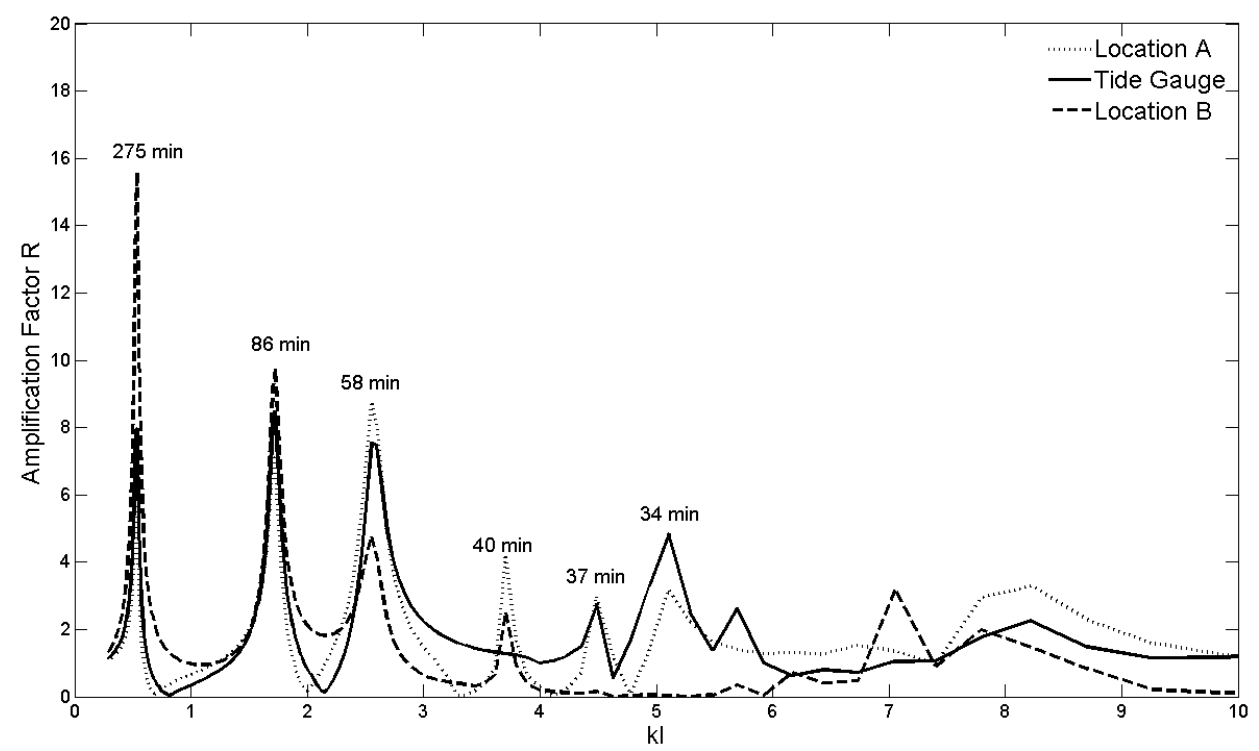

Figure 19. Response curves at San Diego Harbor for different incoming wave directions.

In order to compare the numerical modeling results with the wave records at the tidal gauge station, the time series of water surface oscillations recorded at San Diego Harbor tidal gauge station for the six tsunami events is shown in Figure 20. As seen from Figure 20, the amplitude of water surface oscillations in San Diego Harbor for the Chile earthquake (Feb 27, 2010) and Japan earthquake (Mar 11, 2011) are much larger than other earthquakes. The same phenomena can be observed from the energy spectral density analysis of the six near-field and far-field tsunamis events presented in Figure 21. The computed wave energy spectral density for Chilean and Japan earthquake as shown in Figure 21 (e) and (f) are much greater than those of other earthquakes in Figure 21 (a)-(d). The spectral curves show the existence of resonant periods at around $270 \mathrm{~min}, 88 \mathrm{~min}, 58 \mathrm{~min}, 44 \mathrm{~min}$, and $34 \mathrm{~min}$. This agrees well with the computed resonant periods at the tidal gauge location in San Diego Harbor shown in Figure 19.

From Figure 21 it is seen that the resonant periods can be indentified in all these spectral curves; however the magnitude of the spectral peaks at $\mathrm{T}=58 \mathrm{~min}, 44 \mathrm{~min}$, and $34 \mathrm{~min}$ for 2010 Chilean tsunami and 2011 Japan tsunami are quite different from the four earlier smaller tsunamis. We theorize this apparent difference between the large tsunami and small tsunami at San Diego Harbor as the trapping of wave energy in the harbor due to the long and narrow shape of the San Diego Harbor channel connected to the "U-Turn" channel at the North Bay. Once the tsunami waves are propagated into the harbor it is difficult to radiate out of the harbor due to the orientation of the San Diego Harbor basin. When the tsunami wave energy is small the dominant wave of oscillations is the first mode (pumping mode) inside the harbor as shown in Figure 21 (a)-(d). When the tsunami energy is strong (such as 2010 Chilean tsunami and 2011 Japan tsunami), waves with smaller resonant periods are easily trapped inside the harbor thus setting up the "sloshing mode" of oscillations (Lee and Raichlen 1972). The multiple sloshing modes of oscillations are then generated (such as the modes at $\mathrm{T}=58$ min, $44 \mathrm{~min}, 34 \mathrm{~min}$ ) as shown in Figure 21 (e)-(f).

The present model results show that the resonant modes of oscillation for San Diego Harbor agree well with the tide gauge data for all six tsunamis studied. The strong spectral peaks at $\mathrm{T}=58 \mathrm{~min}, 44$ min, and 34 min for both the Chilean tsunami (2010) and Japan tsunami (2011) are particularly noteworthy.

\section{CONCLUDING REMARKS}

The wave induced oscillations in Crescent City Harbor has been studied and the expected amplification can be reliably computed by the numerical model. Harbors respond to predictable pattern in amplifying waves of certain wave periods which correspond to resonant modes of the harbor.

Oscillations of waves associated with the resonant modes appear every day even though they are at low energy level. Nevertheless, when incident wave trains contain larger wave energy such as tsunami 
events, the water levels inside harbors are amplified according to the response characteristics defined by the harbor shape and the local bathymetry. In some instances, significant amplification can be induced. The multiple peaks of wave spectrum in the tsunami record of Crescent City Harbor for the Chilean earthquake are the results of different wave frequencies (and wave periods) corresponding to a variety of water depths associated with the predicted fundamental resonant modes of oscillation.

The response curves obtained for San Diego Harbor reveal many interesting resonant response to 2010 Chilean tsunami and 2011 Japan tsunami. Significant spectral energy density associated with these two large tsunamis at the "sloshing resonant modes" is the results of energy trapping in the harbor basin due to the special shape and basin orientation of San Diego Harbor.
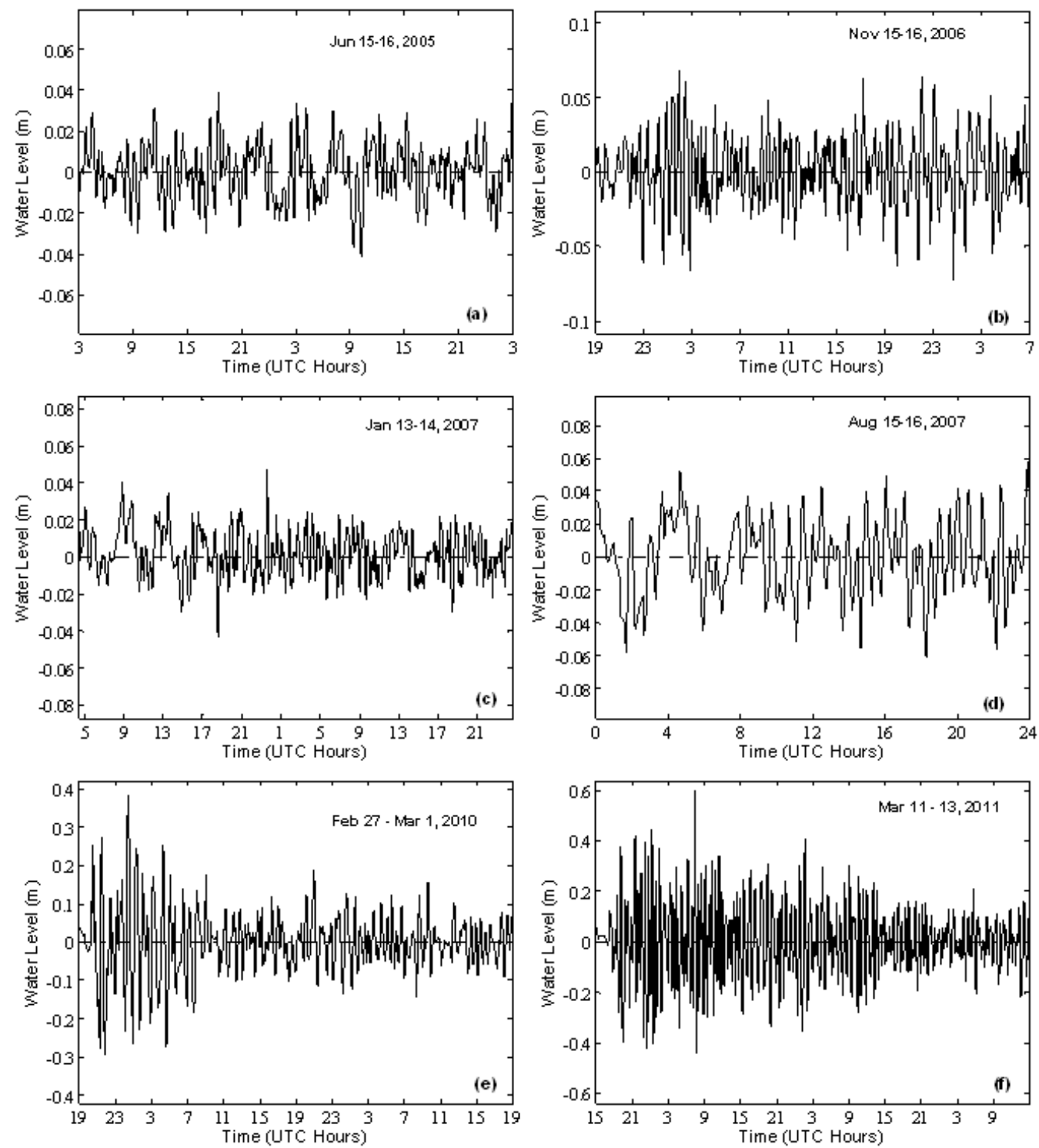

Figure 20. Tidal gauge record without tide effect in San Diego Harbor for events on (a) Jun 15, 2005, (b) Nov 15, 2006, (c) Jan 13, 2007, (d) Aug 15, 2007, (e) Feb 27, 2010, and (f) Mar 11, 2011. 

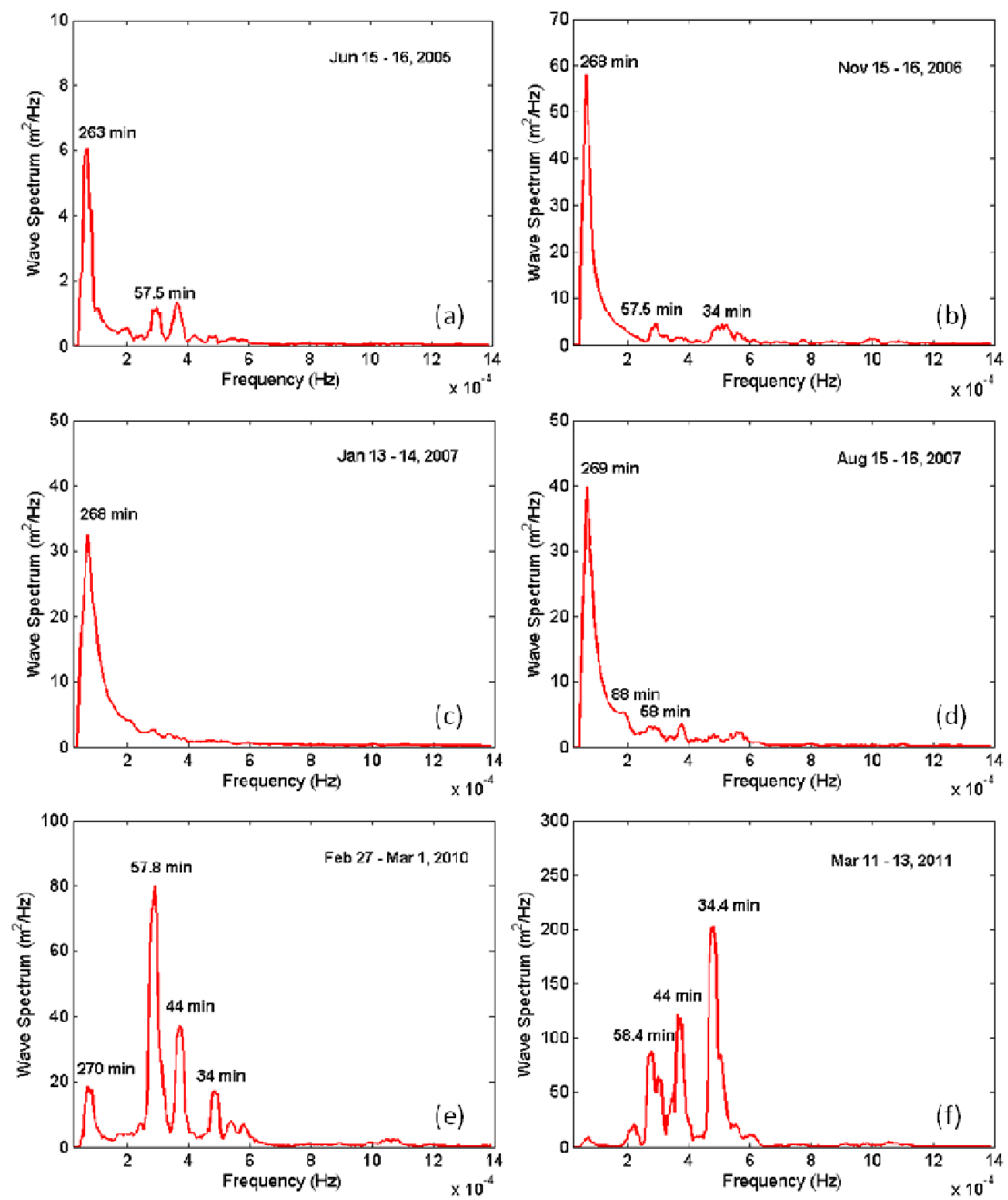

Figure 21. Corresponding spectral density of the tidal gauge records at San Diego Harbor on (a) Jun 15 , 2005, (b) Nov 15, 2006, (c) Jan 13, 2007, (d) Aug 15, 2007, (e) Feb 27, 2010, and (f) Mar 11, 2011.

\section{REFERENCES}

Berkhoff, J.C.W. 1972. Computation of Combined Refraction-diffraction, Proc. 13th Coast. Eng. Conf., ASCE, New York, 471-490.

Gehlken, M., T. Shin, and G. Bledsoe. 2011. Tsunami Causes Boat Damage in San Diego, National Broadcasting Company (NBC), San Diego. http://www.nbcsandiego. com/news/local/TsunamiShatters-Barge-in-San-Diego-Bay-117836593.html.

Lee, J.J. 1971. Wave-induced Oscillations in Harbors of Arbitrary Geometry, J. Fluid Mech., 45(2), 375-394.

Lee, J.J. and F. Raichlen. 1972. Oscillations in Harbors with Connected Basins, ASCE J. Waterway, Ports, Coastal and Ocean Engineering Division, 98(WW3), 311-332.

Lee, J.J. and X.Y. Xing. 2010. Computer Modeling for Harbor Planning and Design, Handbook of Coastal and Ocean Engineering (Edited by Y.C. Kim), World Scientific, 695-722.

Lee, J.J., X.Y. Xing and O. Magoon. 2008. Uncovering the Basin Resonance at Crescent City Harbor Region, Proceedings of ICCE 2008, 2, 1210-1222. 
Magoon, O.T. 1965. Structural Damage by Tsunamis, Coastal Engineering, Satan Barbara Specialty Conference, ASCE, 35-68.

Powers, D.M. 2005. The Raging Sea: The Powerful Account of the Worst Tsunami in U.S. History, Kensington Publishing Corporation.

Raichlen, F. and J.J. Lee. 1992. Oscillation of Bays, Harbors, and Lakes, Handbook of Coastal and Ocean Engineering, Gulf Publishing Company, Chapter 13.

Wilson, R. I., L.A. Dengler, M. R. Legg, K. Long, and K.M. Miller. 2010. The 2010 Chilean Tsunami on the California Coastline, Seism. Res. Lett., 81 (3), 545-546.

Zelt, J.A. and F. Raichlen. 1990. A Lagrangian Model for Wave-induced Harbor Oscillations, J. Fluid Mech., 213, 203-225. 